\title{
O Pronaf na Zona da Mata Mineira: efeitos nos PIBs total e setorial dos municípios ${ }^{1}$
}

\author{
Gabriel Magalhães Rodrigues²
}

Resumo: Este trabalho busca analisar os efeitos do Programa Nacional de Fortalecimento da Agricultura Familiar (Pronaf) nos Produtos Internos Brutos total e setorial da mesorregião da Zona da Mata de Minas Gerais entre 2001 e 2012, levando em conta as características históricas, geográficas, socioeconômicas, produtivas e fundiárias. A importância desse tipo de análise é notória diante da grande dimensão de alcance do programa e da representatividade da agricultura familiar no cenário nacional e nas propriedades rurais da mesorregião. Foi utilizada a Análise de Dados em Painel com efeitos fixos para medir a elasticidade do PIB e dos valores agregados setoriais em relação ao volume de recursos contratados via Pronaf. Chegou-se à conclusão que o programa teve efeito positivo sobre o produto mesorregional, e que o grau desse efeito em cada município está relacionado diretamente a questões institucionais, históricas e econômicas.

Palavras-chaves: políticas públicas, agricultura familiar, Pronaf, Zona da Mata Mineira.

\begin{abstract}
This work aims to analyze the effects of the National Program for Strengthening Family Agriculture (Pronaf) in the Total and Sectorial Gross Domestic Products of Zona da Mata of Minas Gerais mesoregion between 2001 and 2012, taking into account the historical, geographic, socioeconomic, productive and land characteristics. The importance of this type of analysis is notorious because of the large scope of the program and the representativeness of family agriculture in the national scenario and in the rural properties of the mesoregion. Fixed-effects Panel Data Analysis was used to measure the elasticity of GDP and sectorial aggregate values in relation to the volume of resources contracted via Pronaf. It was concluded that the program had a positive effect on the mesoregional product, and that the degree of this effect in each municipality is directly related to institutional, historical and economic issues.
\end{abstract}

Key-words: public policy, family agriculture, Pronaf, Zona da Mata Mineira.

Classificação JEL: R1, R15.

DOI: http://dx.doi.org/10.1590/1234-56781806-94790570102

1. Data de submissão: 12 de julho de 2017. Data de aceite: 26 de fevereiro de 2018.

2. Universidade Federal de Viçosa (UFV). Viçosa-MG, Brasil. E-mail: gabrimagalhaes@gmail.com 


\section{Introdução}

A agricultura familiar é presente e expressiva na região da Zona da Mata Mineira e os espaços rurais, bem como suas populações, passaram ao longo do tempo por transformações no modo de viver e de produzir adaptados às características locais, mas inseridos num sistema global. Essas populações rurais possuem riqueza cultural inestimável, e muitas vezes contribuem para a dinamização e a ocupação dos espaços de maneira a reduzir as degradações ambiental e social. Os agricultores familiares também são responsáveis por parte da produção agropecuária regional, além de movimentarem outros setores principalmente por meio da compra/venda de insumos. Contudo, por diversas razões, uma parcela desses trabalhadores rurais se encontra descapitalizada, sem condições de modernizar, adequar ou expandir sua produção e, na pior das situações, sequer conseguem se manter onde vivem e trabalham.

Nesse sentido, este artigo foi desenvolvido diante da seguinte questão: o Programa Nacional de Fortalecimento da Agricultura Familiar (Pronaf) tem efeito no Produto Interno Bruto (PIB) da mesorregião da Zona da Mata Mineira (ZMM)? Em que medida?

Para além do PIB total, a análise também compreende o Valor Adicionado Bruto (VAB) da agropecuária, indústria e comércio/serviços, nos 142 municípios que compõem a região. Devido à disponibilidade de dados, foi considerado o intervalo fechado entre 2001 e 2012.

A hipótese levantada é de que o programa ajuda a criar condições para que os agricultores familiares possam expandir ou melhorar a produção, o que traz efeitos positivos no PIB regional e no desenvolvimento rural. Portanto, o objetivo geral da pesquisa é identificar e analisar a relação entre o valor dos contratos do Pronaf e a evolução do PIB, e do VAB dos diferentes setores, dos municípios que compõem a mesorregião. O objetivo específico é analisar as características geográficas, sociais e produtivas da mesorregião para a caracterização da Agricultura Familiar.

Este trabalho contribui para a avaliação da política pública referida, para a orientação de mudanças a serem realizadas e também para promover uma alocação mais eficiente dos recursos no processo orçamentário, buscando a ampliação no número de acessos com a melhoria da qualidade de vida e de produção. Um ponto de destaque é a realização da análise proposta por meio de regressões com dados em painel (séries temporais e séries de corte transversal).

Outros trabalhos, como os de Mattei (2007), analisam os efeitos do Programa sobre as economias locais de todas as regiões do Brasil, ou não visualizam um horizonte temporal, como o trabalho de Riceto et al. (2007), que estudam o estado de Minas Gerais, mas apenas em um período do tempo. Por outro lado, Silva (2008) avalia os impactos dos recursos do Pronaf em territórios rurais com baixa dinâmica econômica, especificamente no território rural do Médio Jequitinhonha em Minas Gerais, entre 1999 e 2006. Como resultado encontrou que os recursos do Pronaf estão associados a aumentos do PIB total e do PIB setorial (agrícola, industrial e de serviços) dos municípios daquela região. Foram notados também impactos positivos do Pronaf sobre a geração de postos formais de trabalho, renda média dos trabalhadores, geração de receitas do 
Imposto sobre Circulação de Mercadorias e Prestação de Serviços (ICMS) e sobre o total da arrecadação tributária municipal.

Compreendendo o Pronaf como uma parte componente do arranjo institucional brasileiro, sua análise, assim como a de outras políticas públicas, se torna critério fundamental para a manutenção de um desenvolvimento sustentado. É notória a expansão da agricultura familiar na mesorregião da Zona da Mata mineira que, de acordo com os dados do Censo Agropecuário de 2006 fornecidos pelo Instituto Brasileiro de Geografia e Estatística (IBGE), conta com 70.912 estabelecimentos agropecuários da "categoria".

Diante desta realidade, o Pronaf é tido como meio de estimular os agricultores para que eles consigam realizar investimentos de forma mais simplificada e concreta, por meio de apoio financeiro e técnico. Ele também busca criar melhores condições para a geração de emprego e renda no campo, buscando a melhoria da qualidade de vida. De acordo com Mattei (2006), o programa apresentou resultados notáveis nos estados da região Sul do País, propiciados pela estrutura fundiária, em que a maioria das propriedades é de pequeno e médio portes, pelo trabalho familiar, que tem grande representatividade quando comparada a outras regiões do País, e pelo grau de desenvolvimento na região. No entanto, a região Sudeste também tem se destacado, atraindo gradualmente maiores volumes de recursos, com destaque para Minas Gerais que, de acordo com o Censo Agropecuário de 2006, é o segundo estado com o maior número de estabelecimentos familiares, ficando atrás somente da Bahia.

O Anuário Estatístico do Crédito Rural (1999-2012), disponibilizado pelo Banco Central do Brasil (Bacen), ao considerar a distribuição dos contratos do Pronaf no somatório do período, entre os estados brasileiros e o Distrito Federal, Minas Gerais fica em segundo colocado, com 9,3\% dos contratos. Quando o critério é a participação dos estados e do Distrito Federal nos recursos totais do Pronaf, MG fica na quarta posição, com 12,4\% do volume de recursos. Já a mesorregião da Zona da Mata Mineira, que conta com a agricultura e a pecuária leiteira como base da economia da grande maioria de seus municípios, tem 121.594 agricultores familiares, de acordo com o banco de dados ICMS Solidário (2013), disponibilizados pela Empresa de Assistência Técnica e Extensão Rural do Estado de Minas Gerais (Emater - MG). Isso corresponde a 14,04\% dos agricul- tores familiares do estado, ficando atrás somente das mesorregiões norte de Minas (24,75\%) e sul/sudoeste de Minas (14,83\%).

Assim, observar e ponderar a relação entre o Programa e a produção é um meio, dentre outros, de tornar mais racionais as decisões e de garantir ou não sua credibilidade e continuidade. No entanto, é importante levar em consideração que objetivo do Pronaf não é replicar a mesma lógica do modelo produtivista e, sim, propiciar o desenvolvimento rural sustentável.

\section{Fundamentação teórica}

O debate acerca da importância do crédito para o desenvolvimento econômico é extenso, e muitos autores já se arriscaram na tentativa de descrevê-la e quantificá-la. Aliada a outros fatores, a quantidade de recursos financeiros disponibilizados à população de determinado território é determinada pelo grau de desenvolvimento do território, mas também é determinante dele. Quando se pensa em crédito, é necessário levar em consideração também os juros e suas implicações tanto para os contratantes quanto para o sistema econômico de maneira geral.

Keynes (1936) enfatiza, em sua análise econômica, a manutenção de níveis estáveis de consumo e investimentos por parte dos governos, empresas e famílias, afirmando que, em economias instáveis ou em períodos de crise, os agentes optariam pela liquidez, ou seja, por manter ativos que conservem valor ao longo do tempo e sejam capazes de liquidar dívidas. Diante de determinados cenários considerados de risco ou incertos os agentes tenderiam a investir menos/entesourar mais, o que traria oscilações nos níveis de renda e emprego (preferência pela liquidez). Assim, os juros são tidos como o pagamento por não optar pela liquidez. Cabe, então, ao Estado aplicar remessas de capital diretamente em investimentos, e paralelamente na concessão de linhas de crédito a baixo custo, garantindo a realização de investimentos do setor privado.

Apesar de a visão de Schumpeter (1934) atribuir demasiada importância às grandes empresas e aos líderes para o processo de inovação, ela também considera as distorções e crises inerentes ao capitalismo e atribui importância aos efeitos de longo prazo do crédito. O aumento do poder de compra por parte dos produtores por meio do crédito possibilitaria a eles a rea- 
lização de investimentos e a combinação de novos fatores de produção que, por conseguinte, iriam gerar aumento do produto e do emprego.

Para os pós-keynesianos, o mercado de crédito tem papel ativo na economia, de modo que os diferentes montantes de moeda disponíveis entre as regiões seriam um dos determinantes para as assimetrias regionais. Em territórios onde as expectativas de retorno de investimentos são menores, os agentes tendem a ficar menos dispostos a adquirirem dívidas, reduzindo, assim, a demanda por fundos. Considerando-se o lado da oferta, um cenário de incertezas incentiva os poupadores a manterem ativos de maior liquidez, os quais muitas das vezes não se encontram nas regiões consideradas periféricas, resultando em um fluxo de recursos para outras regiões, isto é, a alta preferência pela liquidez dos poupadores poderá resultar na redução de fundos financeiros para determinado local, e consequente redução da disposição dos bancos em emprestar (DOW; RODRIGUES-FUENTES, 2006).

De maneira análoga, para Stiglitz (2002), as instituições ofertantes de crédito procuram formas de precaução e redução do risco de inadimplência, por meio de arranjos contratuais que maximizem seus lucros. Porém, estes instrumentos utilizados para reduzir as assimetrias de informação no mercado de crédito acabam por limitar o acesso ao financiamento a uma parcela significativa de potenciais tomadores. Esta parcela refere-se, em grande parte, a microempreendedores, empreendimentos recém-constituídos e pequenos produtores.

Portanto, no que diz respeito ao crédito, os mecanismos de mercado podem até mesmo aumentar as disparidades regionais, destacando-se, assim, a importância do Estado em promover e manter linhas de crédito específicas a populações de territórios com baixo dinamismo. Considerando-se a peculiaridade das atividades agropecuárias (riscos relacionados a fatores ambientais e de preço do produto final) e dos agricultores familiares (baixa capitalização e participação importante no emprego rural), de modo geral, conforme afirmam De Conti e Roitman (2011), para além das políticas públicas de assistência técnica, as políticas públicas de crédito também são fundamentais.

Uma vez contextualizada a relação do crédito com a expansão das variáveis reais da economia, e a participação do Estado nesse processo atuando por meio das políticas públicas, cabe aqui pormenorizar este último termo. De maneira simplificada, uma política pública é uma ação, ou não ação tomada por um grupo, que versa sobre a alocação de recursos, fruto de pressões advindas deste mesmo grupo e/ou de outros grupos.

Para Rua (1998), as políticas públicas podem ser definidas como o conjunto das decisões e ações relativas à alocação imperativa de valores e são resultantes da atividade política, envolvendo diversas ações selecionadas de forma estratégica para efetuar as decisões tomadas. Classificando os "atores políticos", a autora afirma que podem ser públicos e privados. São exemplos os políticos (cuja posição resulta de mandatos eletivos), os burocratas (que ocupam cargos que requerem conhecimento especializado e que se situam em um sistema de carreira pública), os empresários (que são capazes de afetar em escala a economia do País), os trabalhadores (que podem se expressar através da ação organizada), os servidores públicos (organizados em sindicatos de servidores públicos), os agentes internacionais (relacionados a questões econômicas e políticas) e a mídia (formadores de opinião que possuem capacidade de mobilizar a ação de outros atores). Esses atores podem ser identificados observando minuciosamente quais agentes têm interesses diretos ou indiretos relacionados à política em questão.

Um problema ou situação que mobilize ação política, constitua uma situação de calamidade, catástrofe ou crise, ou que abra oportunidades para algum ator relevante pode se tornar uma política pública. Após entrar na agenda do governo, e passar pela fase de formulação, o processo de implementação tratará das ações para fazer uma pauta sair do papel e passar a funcionar de fato. A respeito da avaliação formal das políticas públicas, Rua (2000) conceitua que é a análise ordenada de determinados propósitos, baseada em procedimentos científicos de coleta e análise de informação sobre o conteúdo, estrutura, processo, resultados e/ou impactos de políticas, programas, projetos ou quaisquer intervenções planejadas na realidade. $\mathrm{Na}$ visão da autora, a avaliação representaria um potente instrumento de gestão, contribuindo desde o planejamento e formulação de uma mediação, o acompanhamento de sua implementação, os posteriores ajustes a serem adotados, e até mesmo às decisões sobre sua manutenção, aperfeiçoamento, mudança de rumo ou interrupção.

No processo avaliativo das políticas públicas uma ação fundamental é o monitoramento. Rua (2009) 
define essa ação como a análise continuada de uma intervenção quanto aos efeitos, impactos, insumos, processos e produtos. Esse tipo de análise tem a finalidade de otimizar a gestão, visando obter mais eficiência, eficácia e algumas vezes efetividade. A definição de eficiência está mais ligada à análise de custos e prazos esperados comparados aos realizados. Por outro lado, a de eficácia está relacionada à análise da contribuição de um evento para o cumprimento dos objetivos almejados, e em alguns casos essa avaliação é relacionada ao resultado imediato do Programa. Já o conceito de efetividade está intimamente relacionado aos efeitos nas populações em que o Programa contempla, de acordo com a atividade real, os resultados, e a capacidade de produzir um efeito positivo ou negativo.

De maneira prática, analisar o cumprimento, ou não, das metas e orçamentos traçados para o Pronaf seria uma análise de eficiência; a análise da relação entre uma mudança na estrutura do programa (disponibilização de uma nova linha de crédito, por exemplo) e o cumprimento dos objetivos estipulados é uma investigação de eficácia; observar os resultados positivos ou negativos do Programa na produção da região, no desenvolvimento técnico dos agricultores, na melhoria da renda e condições dos produtores, são exemplos de análises de efetividade.

Hoje, no Brasil, é notória a presença de dois tipos de agricultura: a patronal e a familiar. Veiga (1996) define que, na agricultura patronal, o processo produtivo é organizado por um capitalista (que, muitas vezes, arrenda a terra) e executado por multidões de assalariados. Uma boa definição do conceito de agricultura familiar é apontada por Wanderley (1999), como uma forma de produção que combina propriedade e trabalho, assumindo no tempo e no espaço uma diversidade de formas sociais. Nesse tipo de agricultura, a família é proprietária dos meios de produção e as transformações trazidas com a modernização não representam necessariamente uma ruptura com as categorias pré-existentes.

Para efeito de políticas públicas, nos termos da Lei no 11.326 de 2006, no Art. $3^{\circ}$, um agricultor é considerado familiar desde que:

a) não detenha, a qualquer título, área maior do que 4 (quatro) módulos fiscais ${ }^{3}$;

3. O módulo fiscal (ou módulo rural) é uma unidade de medida, expressa em hectare, fixada para cada município, instituída pela Lei no 6.746, de 10 de dezembro de 1979, b) utilize predominantemente mão de obra da própria família nas atividades econômicas do seu estabelecimento ou empreendimento;

c) tenha percentual mínimo da renda familiar originada de atividades econômicas do seu estabelecimento ou empreendimento, na forma definida pelo Poder Executivo;

d) dirija seu estabelecimento ou empreendimento com sua família.

Neste ramo da agricultura, segundo Grisa e Schneider (2015), existiram basicamente três gerações de políticas públicas, sem sequência de tempo definida. A primeira atende a demandas mais agrícolas e agrárias, como crédito rural, garantia de preços mínimos, seguro agrícola e expansão da fronteira agrícola. As políticas da segunda geração têm um viés mais social e assistencial, buscando a redução da pobreza e das desigualdades no meio rural, deixando as questões da inclusão produtiva e do mercado de trabalho em segundo plano. A terceira geração está mais pautada nos mercados para a segurança alimentar e a sustentabilidade ambiental.

Contudo, esta institucionalização é uma conquista relativamente nova. Conforme uma diversidade de discussões em literatura específica, após a Segunda Guerra Mundial intensificou-se o processo de modernização da agricultura, com a implantação de parte do maquinário e dos produtos químicos usados durante a guerra, adaptados para substituírem mão de obra humana e insumos agrícolas. No Brasil, entre meados da década de 1960 até a década de 1980, duas visões distintas predominavam no que diz respeito às reformas na agricultura e estrutura fundiária: a primeira defendia o aumento da produtividade por meio da reforma agrária e a segunda, que se concretizou, visava a adoção de pacotes tecnológicos pelos agricultores, todavia, sem mencionar a questão fundiária. A predominância da segunda visão aumentou a exclusão dos agricultores familiares na participação do cenário econômico brasileiro, tanto pela falta de políticas de microcrédito condizentes à realidade desses agricultores, quanto pela manutenção da concentração de terras ociosas.

que leva em conta o tipo de exploração predominante no município e a renda obtida com a exploração predominante e outras explorações existentes, que sejam expressivas em função da renda ou da área utilizada. 
A década de 1990 foi muito instável no meio rural e acarretou, com o Grito da Terra Brasil (GTB), diversas marchas em Brasília organizadas pela Confederação Nacional dos Trabalhadores da Agricultura (Contag), Central Única dos Trabalhadores (CUT) e Movimento dos Trabalhadores Rurais Sem Terra (MST). O Grito da Terra Brasil foi tido como uma grande ação nacional, diante da necessidade de unificar as lutas dos trabalhadores rurais, debatendo a reforma agrária e melhores condições para a permanência dos agricultores no campo. Antes do GTB não havia políticas públicas específicas para a agricultura familiar, até porque esta não estava institucionalizada como categoria social ou econômica. Com exceção da aposentadoria para o pequeno produtor rural (segurado especial), que fora conquistada na Constituição Federal de 1988, as mesmas linhas de crédito que existiam para as grandes propriedades eram as disponíveis para o agricultor familiar.

Diante da mobilização dos atores políticos, os formuladores de políticas públicas entenderam que os custos da não implantação da política seriam mais altos do que os benefícios e, assim, em 1994, foi criado o Programa de Valorização da Pequena Produção Rural (Provap), prevendo condições especiais para o financiamento do custeio da safra 1994-1995. A pressão continuada dos representantes dos agricultores familiares levou o Provap à revisão, avaliação, adaptação e ampliação, sendo criado, em 1995, o Programa Nacional de Fortalecimento da Agricultura Familiar (Pronaf) ${ }^{4}$, que foi reestruturado por meio de decreto em outubro de 2001.

Em 1996, somente ações relativas ao crédito de custeio foram efetivadas. A expansão para as áreas de investimentos, infraestrutura e serviços municipais, capacitação e pesquisa aconteceu apenas em 1997, quando o Pronaf ganhou maior dimensão e passou a operar de forma generalizada em todo o território nacional. Outras linhas de financiamento do Pronaf foram criadas a partir de 2003, podendo ser citadas: Pronaf Mulher, Jovem, Agroindústria, Agroecologia, Semiárido, Floresta, Eco, Turismo Rural, Pesca e Mais

4. Em 1995, a Resolução CMN/Bacen/no 2.191 estabelece as primeiras condições de acesso à Linha de Ação Pronaf Crédito Rural, exclusiva para o agricultor familiar. Ainda em 1995, por meio da Resolução CMN/Bacen/no 2.223, as operações do Programa Especial de Crédito para a Reforma Agrária (Procera) foram incorporadas pela referida linha de crédito.
Alimentos. Os beneficiários do Programa são classificados em grupos (com condições diferentes de crédito), de acordo com a participação ou não em programas de reforma agrária do governo, renda bruta familiar, contratação ou não de trabalho assalariado permanente e atividade produtiva.

No caso do Pronaf, que é uma política que envolve diferentes regiões de um mesmo país, a implementação pôde se mostrar uma questão problemática, já que o controle do processo se torna mais complexo. Prova disso é que nos anos iniciais do Programa houve forte concentração de financiamento nas regiões Sudeste/ Sul, bem como nos produtores mais integrados economicamente. Com o passar dos anos, o Programa foi se aperfeiçoando, buscando reduzir ou simplificar os trâmites burocráticos, criar mais categorias enquadrando agricultores mais carentes, fortalecer a modalidade infraestrutura, e promover a utilização mais direta dos recursos do Fundo de Amparo ao Trabalhador (FAT) fazendo, finalmente, com que o programa atingisse um público maior (MATTEI, 2006).

Outros trabalhos, de maneira análoga a este, buscaram avaliar esta política pública. Pereira e Nascimento (2014), utilizando o método estatístico de regressão linear pela média e regressão quantílica, avaliaram os efeitos positivos do Pronaf sobre a produção familiar (vegetal e animal) nos municípios tocantinenses entre 2002 e 2009. Os autores também levaram em consideração a distribuição dos recursos do Programa pelo território do estado analisado, percebendo evolução no volume total com o decorrer dos anos, embora existam condições de expansão dado o elevado contingente de agricultores familiares. Diferindo do que indica a análise dos efeitos do Pronaf no PIB dos municípios da Zona da Mata Mineira como será mostrado adiante, no estado do Tocantins não há indícios de que o crédito do programa esteja escorrendo para as microrregiões mais ricas, contribuindo, desta forma, para a redução do hiato entre potencial produtivo e produto efetivo.

Kageyama (2003), por sua vez, buscando analisar os efeitos do Pronaf-crédito na produtividade e renda da agricultura familiar, utilizou dados de 21 municípios em oito estados brasileiros para comparar características econômicas e sociais dos produtores agrícolas familiares que receberam e que não receberam o crédito do Pronaf. Apesar de os resultados não apontarem aumento da renda familiar correlacionado aos recur- 
sos do programa, os agricultores familiares que acessaram o crédito em geral têm maior nível tecnológico e de produtividade. Não desconsiderando a validade da análise, é interessante atentar-se para a temporalidade (apenas o ano de 2002) e o tamanho da amostra frente às proporções continentais e a heterogeneidade do País.

A importância desse Programa é destacada no sentido em que ele busca auxiliar no ajuste das políticas públicas à realidade dos agricultores familiares e viabilizar a infraestrutura necessária para a melhoria do desempenho produtivo. O Pronaf também busca elevar o nível de profissionalização dos agricultores por meio do acesso aos novos padrões de tecnologia e de gestão social e proporcionar o acesso desses agricultores aos mercados de insumos e produtos.

Atualmente, ele conta com três modalidades de crédito: custeio, investimento e comercialização, com juros podendo variar de $0,5 \%$ a $4 \%$ ao ano. Observando o histórico do Programa, de acordo com os dados da evolução do Pronaf, disponibilizados pelo Ministério do Desenvolvimento Agrário (2016), em 1999/2000 foram disponibilizados pouco menos de $\mathrm{R} \$ 3,3$ bilhões com execução de $66 \%$. No ano agrícola de 2003/2004 houve o primeiro grande incremento no montante, sendo ofertados $\mathrm{R} \$ 5,4$ bilhões aos agricultores e com execução de $83 \%$ do valor disponibilizado. Em 2006/2007, o montante disponibilizado para financiamento do Pronaf chegou a R\$ 10 bilhões, com taxa de execução de $84 \%$. Para o período de safra 2014/2015, o governo federal, por meio do Pronaf, disponibilizou $\mathrm{R} \$ 24,1$ bilhões a operações de custeio e investimento.

Além da disponibilização de crédito, serviços técnicos e mercado para escoamento da produção, o Plano de Safra da Agricultura Familiar 2014/2015 contou com algumas possibilidades de solução para endividamentos passados, como renegociação das dívidas e liquidação de dívidas com alta taxa de desconto, por exemplo. No âmbito nacional, para financiar a safra 2015/2016, seriam destinados R 28,9 bilhões por meio do Pronaf, com juros entre $2 \%$ e 5,5\% ao ano. O Plano Safra também prevê atender 230 mil novas famílias de agricultores familiares com assistência técnica e extensão rural. Além disso, os agricultores familiares poderão vender diretamente ao governo federal, às Forças Armadas e às escolas.

\section{A Região da Zona da Mata Mineira}

A mesorregião da Zona da Mata Mineira (ZMM), Região da Mata ou Matas de Minas, está localizada no sudeste de Minas Gerais e conta com 142 municípios, de acordo com a Fundação João Pinheiro (FJP), distribuídos em uma área de $35.229 \mathrm{~km}^{2}$, agrupando-se em sete microrregiões, sendo elas Ponte Nova (18 municípios), Manhuaçú (20), Viçosa (20), Ubá (17), Muriaé (20), Juiz de Fora (33) e Cataguases (14). Marcada pelo relevo rugoso, tem como vegetação nativa a Mata Atlântica, tipo de floresta que foi substituída pelas lavouras de café e, posteriormente por pastagem, e hoje ainda existe somente nos pontos de maior altitude. Possui localização privilegiada, estando entre duas das mais importantes metrópoles do País, Rio de Janeiro e Belo Horizonte. Quanto à infraestrutura de transporte, é servida por importantes rodovias federais, tais como BR-040, BR-116, BR-262 e BR-267 e também é cortada pelas antigas ferrovias Central do Brasil e E.F. Leopoldina.

O povoamento da região iniciou-se no século XVIII, impulsionado pelo declínio da atividade mineradora e expansão da lavoura cafeeira no século XIX, cultura que contribuiu para a dinamização econômica levando ao desenvolvimento dos setores comercial, industrial e financeiro. Com o fim do chamado "primeiro ciclo do café" e início do processo de substituição de importações, a partir de 1930, o estado de Minas Gerais passou por um processo de concentração de investimentos nos setores de extração mineral e produção siderúrgica e, com isso, a Zona da Mata começa a perder o protagonismo econômico e político para outras mesorregiões, principalmente para as que se localizam mais ao centro do estado. Durante esse século, a atividade agropecuária declinou, produzindo estagnação socioeconômica e sucateamento do capital acumulado, sendo que, atualmente, é considerada uma mesorregião pouco industrializada, destacando-se, nesse setor, os polos de Juiz de Fora (automobilística, têxtil e alimentícia), Ubá (moveleira, calçados e têxtil) e Cataguases (têxtil, mineradora, metalúrgica e energia).

De acordo com informações da Fundação João Pinheiro (2012) e do IBGE (2010), a Zona da Mata tem população total de cerca de 2,2 milhões de habi- 
tantes, o que representa $11 \%$ da população mineira. A densidade demográfica média é de $62,44 \mathrm{hab} / \mathrm{km}^{2}$, acima da média do estado de Minas Gerais, que é de $33,41 \mathrm{hab} / \mathrm{km}^{2}$. Dentre essas pessoas, cerca de $80 \%$ residem na área urbana e 20\%, na área rural. Em 2012, a Zona da Mata Mineira tinha PIB de R\$ 30.230.229,00 e PIB per capita anual de cerca de R\$13.741,00. Já o estado de Minas Gerais, no mesmo ano, contava com PIB de R\$ 403.551.317,00 e população de 19.855.332 habitantes, com renda per capita de $\mathrm{R} \$ 20.324,00$.

A participação da Zona da Mata no PIB mineiro foi de 7,49\% em 2011. Quando se analisa por atividades, agropecuária, indústria e serviços geraram, respectivamente, 9,3\%, 5,0\% e 8,8\%. A agropecuária representou $11,3 \%$ do Valor Adicionado (VA) da região e obteve contribuições expressivas da produção de lenha, de carvão vegetal, cultivo de café e da pecuária (bovinos, suínos e aves). Na indústria, que contribuiu com $21,6 \%$ do VA local, teve maior peso a de transformação dos gêneros metalúrgico, têxtil, moveleiro e automobilístico. Os serviços representaram $67,1 \%$ do VA local, destacando-se o comércio, principalmente com as vendas de bebidas (refrigerante e cerveja), café, produtos de perfumaria e cosméticos, combustíveis e automóveis (IBGE, 2011).

A Agenda de Desenvolvimento da Zona da Mata (2011), publicada pela Universidade Federal de Juiz de Fora (UFJF), mostra que Juiz de Fora é a mais importante microrregião e o maior e mais influente polo da Zona da Mata, correspondendo a 33,4\% da população total e metade da participação do PIB industrial e de serviços de tal região. A microrregião de Cataguases/ Leopoldina possui $10 \%$ da população total da Zona da Mata, tendo como principais atividades industriais os setores de confecção, têxteis, alimentar, química e papel e papelão. A microrregião de Muriaé possui 12,7\% da população da região, destacando-se na indústria têxtil-confeccionista. Já a microrregião de Ubá, com 12,3\% da população total, é um dos maiores polos moveleiros do Brasil. Destaca-se, também na microrregião, o município de Visconde do Rio Branco, pela fruticultura desenvolvida e por sediar a Pif Paf, grande empresa do setor alimentício.

Conforme mostram os dados do Censo Agropecuário de 2006, a Zona da Mata mineira contava com 71.631 estabelecimentos agropecuários com agricultura familiar (8.052 tipo A, 15.092 tipo B, 1.016 tipo C, 38.471 tipo D) e 14.806 estabelecimentos agropecuários com agricultura não familiar. A agropecuária é tradicional, ou seja, entrelaça dimensões sociais, econômicas, políticas e culturais. Em geral, é direcionada para o atendimento dos mercados local e regional, com exceções em alguns segmentos como a cafeicultura, a suinocultura e a avicultura, localizadas em áreas específicas, as quais, entretanto, não têm se mostrado capazes de promover um processo dinâmico de crescimento das microrregiões. Além disso, na agropecuária destacam-se a criação de gado leiteiro e plantações de cana-de-açúcar, milho e feijão.

Analisando a dinâmica da agricultura no estado de Minas Gerais, Bastos e Gomes (2010) afirmam que a produção de grãos na região da Mata é explorada, principalmente, em pequenas propriedades, como culturas de subsistência, sendo comercializado apenas o excedente, caso em que se destacam as culturas do arroz, milho e feijão. Para a autora, o café é um produto cuja expressividade regional tem crescido tanto em volume produzido (segunda maior produtora do estado) quanto em qualidade, tendo alcançado reconhecimento internacional, sobretudo nos municípios do leste. A fruticultura, a partir do século XX, tem ganhado espaço como alternativa para os produtores locais, com destaque para a goiaba e a manga; no entanto, pode-se afirmar que a capacidade produtiva local é ainda subutilizada e os potenciais (posição geográfica e malha rodoviária) ainda podem ser mais eficientemente explorados. A mesorregião é também a terceira maior produtora de arroz no estado. Em 2006, o milho era a cultura temporária predominante na agricultura familiar da ZMM (60\% somando Pronaf A e B), enquanto os cafés conilon e arábica eram as principais culturas permanentes (65\% somando Pronaf A e B e $19 \%$, Pronaf D).

Quanto à distribuição das áreas de lavouras entre agricultura familiar e patronal na ZMM, o Censo Agropecuário de 2006 mostra que as lavouras nos estabelecimentos agropecuários com agricultura familiar somavam 240.250 hectares (114.627 permanentes e 125.623 temporárias, desconsiderando as mistas) e o valor da produção vegetal desses estabelecimentos era de R\$ 734.568.232,00. Já a área de lavouras nos estabelecimentos da agricultura não familiar era de 114.475 hectares (72.125 permanentes e 42.350 temporárias,) e o seu valor da produção vegetal era R\$ 488.198.239,00. Esses números mostram que os estabelecimentos da agricultura familiar da ZMM tinham, naquele ano, um valor da produção médio de $\mathrm{R} \$ 3.057,00$ por hectare, e 
os estabelecimentos da não familiar tinham valor próximo de $\mathrm{R} \$ 4.264,00$ por hectare. Ainda em 2006, a área das lavouras nos estabelecimentos com agricultura familiar estava caracterizada por ser $35 \%$ utilizada por agricultores do tipo A, $24 \%$, por agricultores do tipo B, $11 \%$, por agricultores do tipo C e $36 \%$, pelos do tipo D. As áreas de pastagens nesses estabelecimentos somaram 659.532 hectares, ao passo que, nos estabelecimentos com agricultura não familiar, as áreas somaram 666.325 hectares.

O valor da produção animal nesse mesmo ano foi de R\$ 204.139.907 em estabelecimentos agropecuários com agricultura familiar e R \$ 393.162.825,00 nos estabelecimentos com agricultura não familiar. $\mathrm{O}$ valor superior apresentado nos estabelecimentos da agricultura patronal pode estar relacionado à predominância das criações bovina e suína, $54 \%$ e $83,5 \%$ do total de cabeças, respectivamente. Quanto à produção de bovinos, é maioritária na mesorregião a bovinocultura de leite e, nesse segmento, a maioria das cabeças de gado estão em estabelecimentos da agricultura familiar, assim como na avicultura.

A estrutura fundiária do estado de Minas Gerais, de acordo com o Censo Agropecuário (2006), era predominantemente composta por minifúndios $(61,76 \%)$ e pequenas propriedades $(25,63 \%)$. As médias propriedades correspondiam a 8,53\% da estrutura fundiária e as grandes respondiam por 4,08\% da estrutura. É chamado de minifúndio todo imóvel com área cultivável inferior a um módulo fiscal. Esse tipo de propriedade é caracterizado por utilizar o fator de produção mão de obra intensivamente. A pequena propriedade rural, de acordo a Lei no 11.326/2006, é definida como aquela com área entre 1 (um) e 4 (quatro) módulos fiscais. Já as médias propriedades rurais possuem área superior a 4 (quatro) e até 15 (quinze) módulos fiscais. A propriedade que possuir um número acima de 15 módulos fiscais é chamada de latifúndio (grande propriedade).

Segundo o documento Concentração Geográfica da Agricultura Familiar no Brasil (2013), elaborado pela Empresa Brasileira de Pesquisa Agropecuária (Embrapa), o tamanho médio dos estabelecimentos familiares na mesorregião varia predominantemente entre 0,5 e 1,3 módulo fiscal. Historicamente, a forma como se organizou a atividade produtiva provocou grandes impactos na estrutura fundiária, na vegetação e nas relações sociais da ZMM. Segundo Young (1999), o aumento da mão de obra escrava, predominante no cultivo e beneficiamento da cana e, posteriormente café (em seu primeiro estágio) resultou no atraso social dessa região e intensificou a concentração de riquezas e consequentemente de terras.

Na Zona da Mata Mineira, de acordo com o Censo Agropecuário (2006), a área total dos estabelecimentos agropecuários era de 2.238 .568 hectares, 49,6\% utilizados por agricultores familiares e $51,4 \%$ por não familiares. Dentre essas áreas utilizadas pelos agricultores familiares, 92,32\% eram de proprietários, 4,46\% eram de arrendatários, 1,79\% era de parceiros e 1,34\%, de ocupantes.

Foram apresentados os fundamentos teóricos necessários para a compreensão da importância do crédito e das políticas públicas para o desenvolvimento econômico. Também foram contextualizados tanto o programa em questão quanto a delimitação geográfica escolhida. Destarte, é possível avançar à metodologia dos procedimentos estatísticos utilizados para concretizar a análise dos efeitos do Pronaf no PIB total e setorial dos municípios da Zona da Mata Mineira.

\section{Metodologia}

A técnica estatística de dados em painel reúne informações de unidades, indivíduos ou empresas, por exemplo, que podem ser acompanhadas ao longo do tempo. Segundo Duarte, Lamounier e Takamatsu (2007), cada município possui características específicas que influenciam na maneira como eles reagem a estímulos. Estas características afetam a variável que se deseja explicar; porém, não são possíveis de serem mensuradas. No entanto, o uso de dados em painel permite controlar os efeitos das variáveis não observadas.

As regressões em modelo de dados em painel, segundo Gujarati (1998), em geral apresentam-se da seguinte forma:

$$
Y_{i t}=\beta 1_{i t}+\beta 2_{i t} . X 2_{i t}+\ldots+\beta n_{i t} \cdot X k_{i t}+u_{i t}
$$

Em que $i$ representa a i-ésima unidade de corte transversal e $t$ o t-ésimo período de tempo; $\beta 1$ é um intercepto comum; $\beta 2, \beta 3, \ldots, \beta n$ são os vetores dos parâmetros desconhecidos; $X k_{i t}$ refere-se à k-ésima variável explicativa para o indivíduo $i$ no instante de tempo $t$; e $u_{i t}$ é o erro (GUJARATI, 1998).

Todavia, é possível determinar o efeito individual de cada unidade de corte transversal por meio do termo $Z_{i}$ : 


$$
Y_{i t}=Z_{i}+\beta 1+\beta 2 . X 2_{i t}+u_{i t}
$$

Se $Z_{i}$ tem apenas um termo constante, o Modelo de Mínimo Quadrados Ordinários (MQO) gera estimadores consistentes e eficientes para $\beta 1$ e $\beta 2$. Para esse tipo de modelo, adota-se a regressão Pooled, ou dados empilhados, que não considera as características das seções cruzadas e as séries no tempo. No caso de $Z_{i}$ ser não observado, caso seja correlacionado com $X 2_{i t}$, caracteriza-se efeito fixo, do contrário, caracteriza-se como efeito aleatório. Quando para cada indivíduo $i$ temos o mesmo número de dados temporais, o painel chama-se balanceado (ou equilibrado). De outro modo, se o número de dados temporais não é o mesmo para todos os indivíduos, o painel chama-se não balanceado (ou desequilibrado). Esta metodologia ainda proporciona alguns benefícios, destacando-se a heterogeneidade dos indivíduos, maior nível de informação a respeito das variáveis explicativas, menor colinearidade (podendo evitar o problema de multicolinearidade) e maiores graus de liberdade para o modelo (GUJARATI, 1998).

De forma mais simplificada, um conjunto de dados em painel é aquele que segue uma determinada amostra de indivíduos ao longo do tempo, e fornece, assim, diversas observações sobre cada indivíduo na amostra. Assim, os pontos fortes desse tipo de análise são investigar o efeito do tempo nos dados, testar se as relações entre as variáveis mudam com o tempo e acomodar a heterogeneidade, permitindo variáveis específicas para cada unidade cross section. Além disso, pode detectar e medir efeitos mais complexos que não seriam observados por uma análise puramente cross section ou temporal.

O principal objetivo da estimação dos efeitos fixos é controlar as características que são específicas dos indivíduos, mas que não variam durante o tempo da série, além de elementos que são captados por meio de outras variáveis independentes, isto é, o procedimento dos efeitos fixos reduz o viés de variáveis omitidas. Os interceptos $\alpha_{i}$ variam somente de indivíduo para indivíduo e, assim, o modelo consegue capturar as diferentes características entre indivíduos ao longo do tempo.

Esse tipo de modelo, segundo Gujarati (1998), pode ser definido como:

$$
Y_{i t}=\alpha_{i}+\beta 2 . X 2_{i t}+\ldots+\beta n \cdot X k_{i t}+u_{i t}
$$

em que, $\beta 1_{i t}=\beta 1_{i}, \beta 2_{i t}=\beta 2_{i}, \ldots, \beta n_{i t}=\beta n_{i}$.
Dessa forma, $\alpha_{i}$ pode ser interpretado como o efeito das variáveis omitidas pelo modelo. Admite-se que existem vários fatores não observáveis que influenciam os ganhos e/ou perdas dos indivíduos, tais como: inteligência, motivação, dedicação que são difíceis de medir e não existem substitutos próximos. Os efeitos fixos são variáveis omitidas que variam entre os indivíduos, mas não ao longo do tempo (HSIAO, 2003).

Quando se usa efeitos fixos, pressupõe-se que alguma coisa no indivíduo pode viesar ou prejudicar o poder explicativo das variáveis e é necessário, portanto, controlar esse efeito. $\mathrm{O}$ modelo de efeito fixo remove essas características invariantes no tempo das variáveis explicativas para que se consiga analisar o efeito líquido das mesmas. Como vantagem clara de se utilizar esse tipo de modelo têm-se a possibilidade de analisar em que medida a variável dependente para cada unidade de corte transversal diferencia-se da média em corte transversal. Uma desvantagem é que as inferências somente serão possíveis para indivíduos pertencentes à amostra, e a utilização de variáveis dummies (binárias) pode comprometer os graus de liberdade (GUJARATI, 1998).

Cada indivíduo é diferente e, portanto, o termo de erro e a constante (que capta essas características individuais) não deve ser correlacionada com os dos demais indivíduos. Se os termos de erro forem correlacionados, então não se pode adotar efeitos fixos, e esse relacionamento terá que ser modelado (provavelmente usando efeitos aleatórios). Os autores Duarte, Lamounier e Takamatsu (2007) afirmam que, assim como no modelo de efeitos fixos, no modelo de efeitos aleatórios o intercepto varia de um indivíduo para o outro, mas não ao longo do tempo. A diferença entre os dois modelos refere-se ao tratamento do intercepto. O modelo de efeitos variáveis trata os interceptos como variáveis aleatórias, ou seja, os indivíduos sobre os quais se dispõe de dados são amostras aleatórias de uma população maior de indivíduos.

Griffiths, Hill e Judge (1993) sugeriram que os $n$ interceptos serão modelados como:

$$
\beta 1_{i}=\beta K+\alpha_{i}
$$

É importante notar que este intercepto é composto pelo intercepto do modelo de efeitos fixos, $\alpha_{i}$, e por um segundo componente, $\beta K$, que corresponde ao intercepto populacional. Os autores Griffiths, Hill e Judge 
(1993) descrevem esse tipo de modelo da seguinte maneira:

$$
Y_{i t}=\beta K+\beta 2 . X 2_{i t}+\ldots+\beta n \cdot X k_{i t}+e_{i t}
$$

em que $e_{i t}=u_{i t}+\alpha_{i}$ representa o erro.

Em situações em que $e_{i t}$ não é correlacionado com todas as variáveis explicativas, Duarte, Lamounier e Takamatsu (2007) afirmam que o modelo de efeitos aleatórios é mais indicado. As vantagens de se utilizar um modelo de efeitos aleatórios são que se utiliza menos graus de liberdade, devido à menor quantidade de dummies, e a previsão condicional pode ser realizada para a população como um todo. Por outro lado, a condição de ausência de correlação e autocorrelação pode ser muito restritiva.

No caso dos Dados em Painel, após eliminar a possibilidade de utilizar um modelo Pooled por meio do Teste de Chow, é preciso decidir entre o uso de um modelo com Efeitos Fixos ou Aleatórios. O que difere os dois modelos é justamente a correlação ou não dos regressores com os efeitos específicos (heterogeneidades individuais), ou seja, o viés (ALVES et al., 2009).

O teste de Hausman é um bom instrumento para essa tomada de decisão. Nesse teste, de forma prática, a hipótese nula representa ausência de viés e, portanto, a não rejeição desta aponta que o modelo de efeitos aleatórios é mais eficiente, e a rejeição desta representa consistência do modelo de efeitos fixos. A estatística do teste é obtida por meio da seguinte equação:

$H=(\beta \mathrm{EA}-\beta \mathrm{EF})(\mathrm{EF}-\mathrm{EA})-1(\beta \mathrm{EA}-\beta \mathrm{EF})$

Em que $\beta$ EA representa o vetor de coeficientes estimados pelos efeitos aleatórios e $\beta$ EF o vetor de coeficientes estimados por efeito fixo, EF e EA denotam as matrizes de covariância dos modelos respectivos (CAPOBIANGO et al., 2012).
Além do Teste de Hausman é possível também o usar o teste de Breusch Pagan para verificar a hipótese de que não há efeitos aleatórios. Porém, há algumas maneiras práticas para auxiliar na escolha do modelo adequado. Judge et al. (1982) ressaltam que, quando o número de unidades de corte transversal é grande e o número de dados de séries temporais é pequeno, as estimativas pelos dois métodos podem diferir significativamente. Neste caso, é adequado optar pelo modelo de efeitos fixos quando se acredita realmente que as unidades individuais ou de corte transversal da amostra não são extrações aleatórias de uma amostra maior. O modelo, em sua forma geral, pode ser descrito como nas seguintes equações e Quadro 1:

$\mathrm{LOG}(\mathrm{PIB})_{i t}=(\beta 0)_{i}+(\beta 1) \cdot \mathrm{LOG}(\mathrm{PRONAF})_{i t}+$

$+(\beta 2) \cdot \mathrm{LOG}(\mathrm{PRONAF}(-1))_{i t}+$

$+(\beta 3) \cdot \operatorname{LOG}(\operatorname{PRONAF}(-2))_{i t}+e_{i t}$

$\mathrm{LOG}(\mathrm{AGRO})_{i t}=(\beta 0)_{i}+(\beta 1) \cdot \mathrm{LOG}(\mathrm{PRONAF})_{i t}+$ $+(\beta 2) \cdot \mathrm{LOG}(\mathrm{PRONAF}(-1))_{i t}+$

$+(\beta 3) \cdot \operatorname{LOG}(\operatorname{PRONAF}(-2))_{i t}+e_{i t}$

$\mathrm{LOG}(\mathrm{IND})_{i t}=(\beta 0)_{i}+(\beta 1) \cdot \mathrm{LOG}(\mathrm{PRONAF})_{i t}+$ $+(\beta 2) \cdot \mathrm{LOG}(\mathrm{PRONAF}(-1))_{i t}+$

$+(\beta 3) \cdot \operatorname{LOG}(\operatorname{PRONAF}(-2))_{i t}+e_{i t}$

$\mathrm{LOG}(\mathrm{SERV})_{i t}=(\beta 0)_{i}+(\beta 1) \cdot \mathrm{LOG}(\mathrm{PRONAF})_{i t}+$ $+(\beta 2) \cdot \mathrm{LOG}(\operatorname{PRONAF}(-1))_{i t}+$

$+(\beta 3) \cdot \operatorname{LOG}(\operatorname{PRONAF}(-2))_{i t}+e_{i t}$

Em que: $i=$ Município 1; Município 2; ...; Município 142; e $t=2001 ; 2002 ; . . . ; 2012$.

$\mathrm{O}$ trabalho limitou-se à defasagem de duas unidades de tempo, por não ser o objetivo principal do trabalho analisar com precisão o efeito multiplicador do Programa. Apesar disso, a utilização de dois anos de defasagem nos valores contratados pelos agricultores

Quadro 1. Descrição das variáveis

\begin{tabular}{|c|l|}
\hline Variável & \multicolumn{1}{|c|}{ Descrição } \\
\hline PIB & Produto Interno Bruto Total por município da Zona da Mata Mineira \\
\hline AGRO & Valor Agregado Bruto da Agropecuária por município da Zona da Mata Mineira \\
\hline IND & Valor Agregado Bruto da Indústria por município da Zona da Mata Mineira \\
\hline SERV & Valor Agregado Bruto dos Serviços por município da Zona da Mata Mineira \\
\hline Pronaf & Valor total dos contratos do Pronaf por município da Zona da Mata Mineira \\
\hline Pronaf (-1) & Valor total dos contratos do Pronaf defasado em um período por município da Zona da Mata Mineira \\
\hline Pronaf $(-2)$ & Valor total dos contratos do Pronaf defasado em dois períodos por município da Zona da Mata Mineira \\
\hline
\end{tabular}

Fonte: Elaboração própria.

RESR, Piracicaba-SP, Vol. 57, № 01, p. 029-048, Jan./Mar. 2019 - Impressa em Abril de 2019 
permite realizar inferências sobre características acumulativas do Programa. As variáveis que dizem respeito ao PIB total e aos VAB's setoriais foram retiradas das séries do Datagerais (1999-2012) disponíveis no banco de dados da Fundação João Pinheiro-MG. Já os valores dos contratos do Pronaf foram conseguidos no banco de dados da Secretaria de Agricultura Familiar, Sistema de Informações para o Município, ligada ao Ministério do Desenvolvimento Agrário (MDA).

Esse modelo analisa os 142 municípios da Zona da Mata Mineira em um horizonte temporal de 12 anos, o que significa que cada uma das quatro regressões conta com 6.816 observações. É consenso na literatura econômica que o Valor Adicionado ou Valor Agregado (VA) é o valor que determinada atividade agrega aos bens e serviços consumidos no seu processo produtivo. De outra maneira, é a contribuição ao PIB pelas diversas atividades econômicas, obtida pela diferença entre o valor de produção e o consumo intermediário absorvido por essas atividades.

Dessa forma, o PIB é definido como:

$$
\begin{aligned}
& \text { PIB = VABTOT + } \\
& + \text { VAB.ADM.PÚBLICA + IMPOSTOS }
\end{aligned}
$$

$$
\mathrm{VABTOT}=\mathrm{AGRO}+\mathrm{IND}+\mathrm{SERV}
$$

O modelo log-log foi o escolhido para realizar as regressões. Ele pode ser expresso da seguinte forma:

$$
\ln Y=\beta 1+\beta 2 \ln X 2+u
$$

A adoção do modelo log-log, ou duplo-log, leva à interpretação de que um incremento de $1 \%$ em X2 está relacionado à uma variação de $\beta 2 \%$ em $Y$, mantendo tudo o mais constante. Além disso, este tipo de modelo pressupõe que a elasticidade seja constante ao longo de toda a curva. Ou seja, os coeficientes relacionados às variáveis explicativas (PRONAF, PRONAF(-1), PRONAF(-2)) representam a elasticidade da variável dependente em relação a essas variáveis. Para a identificação da autocorrelação entre os resíduos da regressão foi utilizado o teste de Wooldridge, que tem como hipótese nula a ausência de autocorrelação. Já para a identificação da heterocedasticidade em grupo, foi utilizado o teste de Wald, que tem como hipótese nula a ausência de heterocedasticidade. A correção da autocorrelação e da heterocedasticidade foi feita por erros padrão robustos e, assim como todos os outros procedimentos estatísticos e econométricos, realizada no software Stata 11.0.

\section{Resultados e discussão}

Nesta parte do trabalho é apresentada e discutida parte dos resultados obtidos por meio das regressões. Os resultados econométricos complementam a análise empírica e permitem a realização de inferências mais precisas. Contudo, é necessário escolher um modelo estatístico que esteja bem adaptado aos dados utilizados e, para isso, pode-se utilizar o Teste de Hausman, como já foi explicitado. Para todas as variáveis dependentes, PIB total, Valor Adicionado Bruto da agropecuária, indústria e serviços, a probabilidade de não rejeição da hipótese nula, obtida pelo Teste de Hausman, foi de $0 \%$. Assim, o modelo de efeitos fixos foi preferível ao de efeitos aleatórios, dado que a hipótese nula é de que o modelo de efeitos aleatórios é preferível ao de efeitos-fixos. ${ }^{5}$

Para analisar o ajustamento do modelo à amostra é pertinente observar os coeficientes de determinação $\left(R^{2}\right)$, que variam entre 0 e 1 , e indicam, em percentagem, o quanto os modelos conseguem explicar os valores observados. Quanto maior o $\mathrm{R}^{2}$, mais explicativo é o modelo, melhor ele se ajusta à amostra. A seguir, a Tabela 1 mostra os valores dos $\mathrm{R}^{2}$ Within (dentro), Between (entre) e Overall (geral).

O R ${ }^{2}$ Within é a soma dos quadrados das diferenças entre as observações de cada município e a suas médias em cada município. Já o $\mathrm{R}^{2}$ Between é a soma do quadrado da diferença entre as médias de cada município e a média de toda a amostra. Já o $\mathrm{R}^{2}$ Overall é a soma, para todos os municípios e anos, do quadrado da diferença entre cada observação de PRONAF, PRONAF(-1), PRONAF(-2), e suas médias. Quando foram analisados os coeficientes de determinação para a regressão do PIB $x$ PRONAF, PRONAF(-1) e PRONAF(-2), o maior valor foi apresentado pelo $\mathrm{R}^{2}$ Within (menores desvios das observações anuais em relação às médias de seus respectivos municípios), o qual sugere que $71 \%$ da variável dependente consegue ser explicada pelos regressores presentes no modelo. Na regressão VABAGRO $x$ PRONAF, PRONAF(-1), PRONAF(-2), o melhor ajustamento foi encontrado no $\mathrm{R}^{2}$ Between (menores desvios

5. Nos casos em que o Teste de Hausman gerou sinal negativo ou uma matriz não positiva definida, seguiu-se uma das orientações do prof. Mark Schaffer da Heriott-Watt University (Edimburgo), de substituí-lo por um teste similar realizado com a aplicação do comando xtoverid no software Stata, que produz um resultado necessariamente positivo e de interpretação similar à do Teste de Hausman. 
Tabela 1. Coeficientes de determinação das regressões $\left(R^{2}\right)$

\begin{tabular}{lcccc}
\hline \multicolumn{1}{c}{$\mathbf{R}^{2}$} & $\begin{array}{c}\text { PIB } x \text { PRONAF } \\
\text { PRONAF(-1) }\end{array}$ & $\begin{array}{c}\text { VABAGRO } \times \text { PRONAF } \\
\text { PRONAF(-1) } \\
\text { PRONAF(-2) }\end{array}$ & $\begin{array}{c}\text { VABIND } x \text { PRONAF } \\
\text { PRONAF(-1) } \\
\text { PRONAF(-2) }\end{array}$ & $\begin{array}{c}\text { VABSERV x PRONAF } \\
\text { PRONAF(-1) } \\
\text { PRONAF(-2) }\end{array}$ \\
\hline Within & 0,7135 & 0,5968 & 0,5968 & 0,7264 \\
Between & 0,2313 & 0,6754 & 0,1218 & 0,1963 \\
Overall & 0,2916 & 0,6288 & 0,1766 & 0,2655 \\
F (3,141) & 358,36 & 185,23 & 241,40 & 425,61 \\
\hline
\end{tabular}

Fonte: Resultados da pesquisa.

das médias municipais em relação à média da Zona da Mata), o qual indica que $67 \%$ da variável dependente consegue ser explicada pelos regressores presentes no modelo.

Analisando o ajustamento na regressão VABIND $x$ PRONAF, PRONAF(-1), PRONAF(-2), o melhor valor de $\mathrm{R}^{2}$ foi o Within, apontando que $59 \%$ da variável dependente está sendo explicada pelos regressores. Por fim, na regressão VABSERV x PRONAF, PRONAF(-1), PRONAF(-2), o melhor ajustamento foi identificado também no $\mathrm{R}^{2}$ Within, que indica que $72 \%$ da variável dependente consegue ser explicada pelos regressores presentes no modelo.

Para analisar os efeitos do Pronaf na produção agregada e setorial na Zona da Mata Mineira, levou-se em conta a correlação dos recursos do programa com os PIBs total e setorial (agrícola, industrial e serviços) dos municípios dessa região, através de quatro regressões. O Pronaf pode ser caracterizado como uma política setorial (agropecuário); no entanto, é pertinente analisar também os impactos desse Programa no produto agregado e em cada setor da economia. A Tabela 2 apresenta os resultados dos parâmetros estimados para PRONAF, PRONAF(-1), PRONAF(-2), e o termo intercepto comum a todos os municípios.

É importante ressaltar que, nas quatro regressões, os três coeficientes estimados mais o termo intercepto comum são estatisticamente significativos ao nível de $1 \%$. Além disso, o sinal positivo dos coeficientes condiz com a teoria, indicando uma relação positiva entre o valor de créditos do Pronaf e o valor da produção.

Quanto ao PIB total da Zona da Mata, os resultados da regressão apontam que, para uma variação de $1 \%$ no montante total de créditos do Pronaf, ocorrerá uma variação positiva de $0,17 \%$ no valor do PIB total da região. Analisando o Pronaf com um ano de defasagem no PIB total, o valor estimado do coeficiente mostrou que $1 \%$ de variação nos recursos do Programa levarão a um aumento de $0,08 \%$ no PIB total do ano seguinte. Já o impacto do Pronaf com dois anos de defasagem indica que $1 \%$ de variação no Pronaf levará a 0,10\% de variação no PIB total do segundo ano seguinte.

Desse modo, quanto ao PIB total, o impacto do Pronaf é maior no ano em que o recurso é disponibilizado, indicando que os agricultores realizam investimentos, seja na compra de máquinas, sementes, fertilizantes, no transporte dos insumos ou na construção de infraestrutura necessária. No ano seguinte à disponibilização dos recursos, o PIB total da Zona da Mata é menos afetado do que no próprio ano ou dois anos depois, pelo fato de que os agricultores estão no período de espera pela safra e, portanto, os maiores investimentos já foram realizados. Apesar disso, o parâmetro correspondente aos recursos disponibiliza-

Tabela 2. Resultados das regressões

\begin{tabular}{|c|c|c|c|c|}
\hline Parâmetros & PIBTOT & VABAGRO & VABIND & VABSERV \\
\hline Intercepto & $\begin{array}{c}5,951225 \\
(0,162225)\end{array}$ & $\begin{array}{c}4,788199 \\
(0,196690)\end{array}$ & $\begin{array}{c}3,329383 \\
(0,195290)\end{array}$ & $\begin{array}{c}5,352481 \\
(0,155005)\end{array}$ \\
\hline PRONAF & $\begin{array}{c}0,178447 \\
(0,014741)\end{array}$ & $\begin{array}{c}0,176192 \\
(0,016192)\end{array}$ & $\begin{array}{c}0,201400 \\
(0,018797)\end{array}$ & $\begin{array}{l}0,1686636 \\
(0,014254)\end{array}$ \\
\hline PRONAF(-1) & $\begin{array}{c}0,084254 \\
(0,011572)\end{array}$ & $\begin{array}{c}0,073620 \\
(0,012519)\end{array}$ & $\begin{array}{c}0,087639 \\
(0,014015)\end{array}$ & $\begin{array}{l}0,0798501 \\
(0,011593)\end{array}$ \\
\hline PRONAF(-2) & $\begin{array}{c}0,105335 \\
(0,010939)\end{array}$ & $\begin{array}{c}0,078819 \\
(0,011129)\end{array}$ & $\begin{array}{l}0,113572 \\
(0,16170)\end{array}$ & $\begin{array}{l}0,1232049 \\
(0,011432)\end{array}$ \\
\hline
\end{tabular}

Fonte: Resultados da pesquisa. 
dos pelo Pronaf com defasagem de dois anos, se mostra mais expressivo do que o defasado em apenas um ano, sendo possível dessa forma, destacar o efeito acumulativo intertemporal da política.

Os números referentes aos efeitos fixos também mostram que existem outras variáveis não observáveis que podem definir maior ou menor impacto do Pronaf em cada município, em relação à média. Os cinco municípios que apresentaram maior efeito-fixo em relação à média foram Juiz de Fora, Matias Barbosa, Ubá, Cataguases e Além Paraíba, conforme mostra a Tabela 3.

Como já abordado anteriormente, os efeitos fixos representam características intrínsecas dos municípios e, dessa forma, o município de Juiz de Fora, por apresentar o maior PIB da mesorregião, elevada população, junto a um elevado grau de desenvolvimento dos setores econômicos, com destaque para o setores de indústria e serviços, apresentou o maior valor. A infraestrutura deixada pela cafeicultura e a privilegiada localização geográfica contribuem para esse resultado. Localizado na microrregião de Juiz de Fora está o município de Matias Barbosa, que apresentou o segundo maior valor de efeito fixo, por sua proximidade ao maior polo da mesorregião desenvolveu a indústria e a agroindústria, destacando-se também no setor de serviços. O terceiro maior efeito fixo foi apresentado pelo município de Ubá, pelo consolidado polo moveleiro (o maior do estado de Minas Gerais) e também devido ao setor de comércio e serviços em expansão.
Os menores efeitos fixos encontrados foram para os municípios de Antônio Prado de Minas (microrregião de Muriaé), Oliveira Fortes (Juiz de Fora), Simão Pereira (Juiz de Fora), Silverânia (Ubá), Pedra do Anta (Viçosa), Sem Peixe (Ponte Nova), Lamim (Viçosa) e São José do Mantimento (Manhuaçú). Foi possível observar que esses munícipios são de baixa população e dinâmica econômica, podendo estar localizados próximos, ou não, da capital da microrregião. Já os municípios que apresentaram maiores efeitos fixos, em geral, são municípios de maior porte, que ofertam quantidades mais elevadas de bens e serviços e têm melhor circulação das informações específicas.

Passando à análise dos efeitos do Pronaf no VABAGRO, $1 \%$ de variação nos recursos do Programa apontam 0,17\% de oscilação no VABAGRO do mesmo ano, ao passo que variam em $0,07 \%$ e $0,08 \%$ no VABAGRO do ano seguinte e de dois anos depois, respectivamente. Assim como na análise feita anteriormente, o primeiro ano foi o que apresentou resultados mais expressivos; no entanto, um indício de efeito intertemporal também pôde ser notado. A relação dos recursos do Programa com o VABAGRO se dá por meio da aquisição de insumos e outras operações, em geral, relacionadas ao custeio agrícola.

Na Tabela 4, nota-se que os cinco municípios que alcançaram um maior efeito-fixo em relação à média foram Leopoldina, Lima Duarte, Urucânia, Manhuaçú e Juiz de Fora.

Tabela 3. Efeitos fixos municipais, regressão PIB total x Recursos do Pronaf

\begin{tabular}{ccc}
\hline Posição & Município & Efeito Fixo \\
\hline $1^{\underline{o}}$ & Juiz de Fora & 4,69 \\
$2^{\underline{o}}$ & Matias Barbosa & 3,00 \\
$3^{\underline{o}}$ & Ubá & 2,75 \\
$4^{\underline{o}}$ & Cataguases & 2,57 \\
$5^{\underline{o}}$ & Além Paraíba & 2,45 \\
\hline
\end{tabular}

Fonte: Resultados da pesquisa.

Tabela 4. Efeitos fixos municipais, regressão VAB agropecuária x Recursos do Pronaf

\begin{tabular}{ccc}
\hline Posição & Município & Efeito Fixo \\
\hline $1^{\mathrm{o}}$ & Leopoldina & 1,25 \\
$2^{\mathrm{o}}$ & Lima Duarte & 1,184 \\
$3^{\mathrm{o}}$ & Urucânia & 1,181 \\
$4^{\mathrm{o}}$ & Manhuaçú & 1,17 \\
$5^{\mathrm{o}}$ & Juiz de Fora & 1,13 \\
\hline
\end{tabular}

Fonte: Resultados da pesquisa. 
Apesar da minoritária participação da agropecuária no PIB, o município de Leopoldina, localizado na microrregião de Cataguases, apresentou o maior valor de efeito fixo quando foi regredido o VABAGRO em função dos valores dos contratos do Pronaf. Isso pode ter ocorrido pela representatividade da pecuária de leite, criação de galináceos e suínos e também pela considerável produção de milho, arroz, banana, cana-de-açúcar e outros. A infraestrutura deixada pelo período das lavouras de café também pode ter influenciado nesse resultado. O município de Lima Duarte apresentou o segundo maior efeito fixo, com um dos maiores PIBs de sua microrregião (Juiz de Fora), tendo a agropecuária como o segundo setor mais relevante da economia municipal, com destaque para a criação de bovinos e galináceos e para as lavouras de feijão, milho e cana-de-açúcar.

Em terceiro lugar está o município de Urucânia, localizado na microrregião de Ponte Nova, cuja economia é baseada no setor agropecuário e de serviços, com destaque para a produção de cana-de-açúcar, sediando inclusive a usina Jatiboca. Outra atividade que movimenta a economia deste município é a suinocultura. É importante chamar atenção para o quarto colocado, o município de Manhuaçu, que apresenta características estruturais positivas por ter sido, e ainda ser, grande produtor e exportador de café.

Esses cinco municípios apresentaram efeito fixo maior que um. Observando os municípios que apresentaram efeito fixo elevado para a agropecuária, foi possível concluir que eles não necessariamente possuem grande tamanho e população, e muitos estão localizados na microrregião de Manhuaçú. Em sua maioria, o setor da agropecuária é o segundo mais representativo, ficando atrás do setor de serviços.

Os municípios que apresentaram os efeitos fixos mais baixos, em geral, têm pequena população (cerca de 5 mil habitantes), predomínio do setor de serviços no PIB, e não estão localizados na mesma microrre- gião. Alguns deles são Lamin (microrregião de Viçosa), Pedra do Anta (Viçosa), Rodeiro (Ubá), Rio Doce (Ponte Nova), Antônio Prado de Minas (Muriaé), Oliveira Fortes (Juiz de Fora) e Dom Silvério (Ponte Nova).

Quando se trata dos impactos do volume de recursos do Pronaf no VABIND, uma alteração de $1 \%$ no Pronaf leva a $0,20 \%$ de variação no VABIND do mesmo ano, 0,09\% no ano seguinte e $0,11 \%$ dois anos após.

Novamente, o ano em que são disponibilizados os recursos é o que tem o coeficiente mais elevado, e a evidência de efeito intertemporal também pode ser notada. O setor industrial, de acordo com os resultados das regressões, é o mais impactado no ano em que são disponibilizados os recursos e no ano seguinte. Isso demonstra que, apesar de o Pronaf ser uma política setorial específica do setor agropecuário, ele pode provocar efeito em outros setores e no PIB total, visto que o setor industrial representa cerca de $20 \%$ do PIB mesoregional.

Os cinco municípios que apresentaram os maiores efeitos fixos em relação à média foram Juiz de Fora, Ubá, Cataguases, Visconde do Rio Branco e Matias Barbosa, como demonstrado na Tabela 5.

As avançadas infraestruturas física, bancária e comercial, junto à privilegiada localização, propiciaram gradativamente ao município de Juiz de Fora uma expansão do mercado de trabalho e, dessa forma, o surgimento de unidades fabris, inicialmente manufatureiras e posteriormente mecanizadas. Hoje, esse município é considerado polo industrial, e esse setor é o segundo mais relevante de sua economia, contando com um Distrito Industrial em operação, destacando-se a fabricação de alimentos e bebidas, produtos têxteis, metalurgia, montagem de veículos e outros. Juiz de Fora apresentou um efeito fixo para a indústria muito superior aos demais municípios da mesorregião.

O município de Ubá, segundo colocado, tem destaque na produção de móveis e têxteis, com o setor industrial sendo o segundo mais representativo no

Tabela 5. Efeitos fixos municipais, regressão VAB indústria x Recursos do Pronaf

\begin{tabular}{ccc}
\hline Posição & Município & Efeito Fixo \\
\hline $1^{\mathbf{o}}$ & Juiz de Fora & 5,40 \\
$2^{\underline{o}}$ & Ubá & 3,63 \\
$3^{\underline{o}}$ & Cataguases & 3,41 \\
$4^{\underline{o}}$ & Visconde do Rio Branco & 3,19 \\
$5^{\mathbf{o}}$ & Matias Barbosa & 3,05 \\
\hline
\end{tabular}

Fonte: Resultados da pesquisa. 
PIB municipal. Considerado polo moveleiro, a cidade atrai capital e fomenta investimentos, uma vez que já existe mão de obra qualificada, e até mesmo maquinário reutilizável, disponíveis. O terceiro maior efeito fixo na regressão do VABIND em função dos recursos contratados via Pronaf foi apresentado pelo município de Cataguases. Esse município se destaca pelas indústrias de tecelagem, reciclagem, mineração, produção de algodão e metalurgia. Além disso, Cataguases também é sede da empresa Energisa, importante no setor elétrico e presente em diversas regiões do Brasil.

Dentre os dez municípios que apresentaram os maiores efeitos fixos, cinco são as maiores cidades das microrregiões (Juiz de Fora, Ubá, Cataguases, Ponte Nova e Muriaé). Os municípios que obtiveram os maiores efeitos fixos, em geral, estão nas microrregiões de Juiz de Fora, Cataguases e Ubá. Os menores efeitos fixos, em geral, foram apresentados por municípios de população pequena (entre 2.000 e 6.000 habitantes) em que a indústria é o setor menos representativo ou tem pouca representatividade. Esses municípios estão dispersos em diferentes microrregiões, porém Manhuaçu, Muriaé e Juiz de Fora abrangem a maior parte deles. Como exemplo é possível citar os municípios de Sem Peixe, Simão Pereira, Silverânia, Pedra Dourada, Antônio Prado de Minas, Oliveira Fortes, Vieiras, Luisburgo e Pedra Bonita.

Assim como nas outras regressões, o Pronaf também traz impactos positivos sobre o VABSERV. Uma alteração de $1 \%$ nos recursos do programa traz $0,16 \%$ de variação no VABSERV do mesmo ano, ao passo que altera $0,07 \%$ e $0,12 \%$ no ano seguinte e dois anos depois, respectivamente.

Mesmo que o setor de serviços tenha apresentado parâmetro inferior, quando comparado ao efeito dos recursos do Pronaf no ano de contratação no setor industrial, os efeitos do volume contratado de recursos no ano de contratação são notórios, visto que o PIB de serviços representa cerca de $68 \%$ do PIB mesorregional. Além disso, esse setor é o que demonstra ser mais afetado pelos efeitos intertemporais da política, apresentando o maior parâmetro referente aos recursos do programa com dois anos de defasagem.

Observando os efeitos fixos da regressão dos Valores Adicionados Brutos dos Serviços contra o volume de recursos acessados pelos agricultores por meio do Pronaf, mostrados na Tabela 6, os cinco municípios que mais se destacaram foram Juiz de Fora, Matias Barbosa, Ubá, Além Paraíba e Cataguases. O município de Juiz de Fora é o primeiro colocado, sendo que tem como setor mais representativo o de comércio e serviços que atrai população das cidades vizinhas e até mesmo de outras microrregiões, por oferecer serviços que requerem alto grau de especialização (principalmente na área da saúde e educação). O pequeno município vizinho, Matias Barbosa, fica com a segunda colocação, muito pela proximidade geográfica do polo, mas também pela predominância do setor de serviços no PIB municipal. Na terceira posição ficou o município de Ubá, no qual a atividade industrial emprega boa parte da população, mas também encadeia no surgimento de diversas outras atividades no setor de serviços (mecânicas de caminhões e comércio de móveis, por exemplo), que apresenta maior participação no PIB municipal.

Dentre os dez municípios que apresentaram os maiores efeitos fixos, sete são as maiores cidades de cada microrregiões. Esses municípios, em sua maioria, possuem elevado contingente populacional, e assim como a grande maioria dos municípios da Zona da Mata Mineira e do estado de Minas Gerais, possuem os serviços como atividade mais representativa em termos de PIB, excluindo-se da análise a participação da administração pública. A parte centro-sul da mesorregião tem um número elevado de municípios que apresentaram altos efeitos fixos relacionados aos serviços.

Tabela 6. Efeitos fixos municipais, regressão VAB serviços x Recursos do Pronaf

\begin{tabular}{ccc}
\hline Posição & Município & Efeito Fixo \\
\hline $1^{\underline{o}}$ & Juiz de Fora & 4,75 \\
$2^{\mathrm{o}}$ & Matias Barbosa & 3,25 \\
$3^{\mathrm{o}}$ & Ubá & 2,74 \\
$4^{\mathrm{o}}$ & Além Paraíba & 2,69 \\
$5^{\mathrm{o}}$ & Cataguases & 2,56 \\
\hline
\end{tabular}

Fonte: Resultados da pesquisa. 
O perfil dos municípios que apresentaram efeitos fixos mais baixos é pequena população (até 5.000 habitantes) e setor de serviços mais representativo em termos de PIB, seguido pela agropecuária, lembrando que esta análise não leva em consideração a contribuição da administração pública. Quanto à localização desses municípios, não se pôde perceber nenhuma relação com os baixos valores, exceto que, entre os dez menores resultados, quatro municípios estão na microrregião de Muriaé. Os menores efeitos fixos foram obtidos pelos municípios de Antônio Prado de Minas (microrregião de Muriaé), Oliveira Fortes (Juiz de Fora), Simão Pereira (Juiz de Fora), Silverânia (Ubá), Sem Peixe (Ponte Nova), São Sebastião da Vargem Alegre (Muriaé), Vermelho Novo (Ponte Nova), Pedra do Anta (Viçosa), Vieiras (Muriaé) e Pedra Dourada (Muriaé).

\section{Conclusões}

Este trabalho foi elaborado na perspectiva de analisar a dinâmica de uma política pública brasileira que envolve o ambiente dos agricultores familiares. Nesse contexto, buscou-se verificar se, em especial, o Programa Nacional de Fortalecimento da Agricultura Familiar (Pronaf) possui o potencial de proporcionar impactos positivos na economia da Zona da Mata Mineira. Essa região de municípios heterogêneos, que possui, em geral, desenvolvimentos social e econômico médios e protagonismo do setor de serviços, tem $20 \%$ dos residentes na área rural, sendo que $50 \%$ das propriedades dessa área são utilizadas por agricultores familiares e estes detêm a maioria das áreas de lavouras e das cabeças de bovinos de leite.

O texto trata de tema relevante para a área e resgata avanços importantes nas políticas públicas para a agricultura familiar. Além disso, apresenta, em avaliação detalhada, os efeitos do Pronaf em mais uma região do País. Chegou-se à conclusão que o Pronaf foi capaz de trazer impactos positivos para o Produto Interno Bruto da região. O volume de crédito e os serviços de assistência técnica disponibilizados por meio do Programa estão relacionados ao maior valor agregado dos produtos e serviços e à maior produtividade. Esse crédito pode proporcionar o aumento da demanda e do fornecimento de insumos por parte dos agricultores e dos estabelecimentos comerciais locais, além de servir como fonte de liquidez para consumo e investimentos.
O Pronaf também aparentou ter efeitos intertemporais acumulativos, impactando no produto dos anos seguintes à aquisição do crédito. Esse comportamento pode estar relacionado ao ciclo de produção agropecuária, em que investimentos realizados em determinado ano só trarão retornos nos anos seguintes, ou também ao efeito multiplicador que será maior diante de um maior volume de recursos contratados.

Foi possível notar que características tais como elevado contingente populacional, privilegiada localização geográfica, composição do PIB e proximidade aos polos microrregionais, em geral, estão relacionadas a melhores respostas do Programa no produto dos municípios. Outra percepção crível é que o Pronaf teve efeito semelhante no Valor Adicionado dos diferentes setores (agropecuária, indústria e serviços).

Todavia, para inferir sobre os efeitos de determinado programa em uma região, é importante que sejam observadas também as características históricas, populacionais, geográficas, econômicas e institucionais. Ademais, no caso dessa pesquisa em especial, para obter conclusões mais precisas dos efeitos do Pronaf no desenvolvimento rural, outras variáveis devem ser consideradas como o comportamento dos agentes financeiros e técnicos de cada município, o grupo de classificação do agricultor familiar e sua opinião a respeito do Programa, e a variação de indicadores de renda e ocupação das populações diretamente relacionadas ao crédito, por exemplo.

Na Zona da Mata Mineira, o maior número de estabelecimentos de agricultores familiares era dos Grupos D e B, os quais se encontravam descapitalizados ou em processo de capitalização, com carência de bens de consumo e serviços a serem adquiridos fora de sua propriedade e que não estão diretamente relacionados ao processo de produção. Diante disso, é importante reformular a forma de fornecimento de crédito, buscando minimizar o "vazamento" desses recursos para atividades não relacionadas à produção ou vinculando linhas de crédito e serviços do Pronaf a outras políticas que objetivam a redução da pobreza rural por meio de ações integradas.

Não é possível pensar em alternativas de desenvolvimento que desconsiderem a realidade rural, uma vez que este espaço e o urbano interligam-se e complementam-se, numa relação dialética. Assim, analisar as políticas públicas e suas interações com a economia de determinada região é um procedimento que 
auxilia no entendimento de particularidades, na definição de caminhos a serem seguidos e na efetividade dos programas.

\section{Referências}

ALVES, D. C. O. et al. Estimação da Elasticidade-Preço da Demanda dos Clientes Comerciais e Industriais da SABESP. Companhia de Saneamento Básico do Estado de São Paulo. Fundação Instituto de Pesquisas Econômicas (FIPE). 2009. 116 p.

BANCO CENTRAL DO BRASIL - BCB. Anuário Estatístico do Crédito Rural (1999-2012). Disponível em: <http://www.bcb.gov.br/?RELRURAL>. Acesso em: 3 ago. 2015.

BASTOS, S. Q. A.; GOMES, J. E. Dinâmica da agricultura no Estado de Minas Gerais: análise diferencial-estrutural para o período 1994 a 2008. 2010. 22 p.

BRASIL. Decreto presidencial no 1.946 , de 28 de julho de 1996. Cria o Programa Nacional de Fortalecimento da Agricultura Familiar - PRONAF, e dá outras providências. Disponível em: < http://www.planalto. gov.br/ccivil_03/decreto/D1946.htm>. Acesso em: 5 ago. 2015.

. Lei no 11.326 , de 24 de julho de 2006. Estabelece as diretrizes para a formulação da Política Nacional da Agricultura Familiar e Empreendimentos Familiares Rurais. Diário Oficial da União. Brasília, DF, Seção 1, 25 jul., 2006, p. 1.

Ministério do Desenvolvimento Agrário (MDA). Evolução do Pronaf (2016). Disponível em: <http://www.mda.gov.br/sitemda/secretaria/ saf-creditorural/evolu \% C3\% A7\% C3\% A3o-dopronaf\#sthash.23tF50IX.dpuf $>$. Acesso em: 9 jun. 2016.

CAPOBIANGO, R. P. et al. Análise do Impacto Econômico do Crédito Rural na microrregião do Pirapora. Rev. Econ. Sociol. Rural, Brasília, v. 50, n. 4, out./dez. 2012.

DE CONTI, B. M.; ROITMAN, F. B. Pronaf: uma análise da evolução das fontes de recursos utilizadas no programa. Revista do BNDES, Rio de Janeiro, n. 35, p. 131-168, 2011.

DOW, S.; RODRIGUES-FUENTES, C. J. Um "survey" da literatura de finanças regionais. In: CROCCO, M.; JAYME JR, F. G. (Orgs.) Moeda e território: uma interpretação da dinâmica regional brasileira. Belo Horizonte: Autêntica, 2006. 344 p.
DUARTE, P. C.; LAMOUNIER, W. M.; TAKAMATSU, R. T. Modelos econométricos para dados em painel: aspectos teóricos e exemplos de aplicação à pesquisa em contabilidade e finanças. In: Congresso USP de controladoria e contabilidade, 7, São Paulo, 2007. Anais USP 2007. São Paulo, 2007. p. 1-15.

EMPRESA BRASILEIRA DE PESQUISA AGROPECUÁRIA (EMBRAPA). Concentração Geográfica da Agricultura Familiar no Brasil (2013). Disponível em: $<$ http://ainfo.cnptia.embrapa.br/digital/bitstream/ item/88745/1/doc-155.pdf $>$. Acesso em 10 de julho de 2015.

EMPRESA DE ASSISTÊNCIA TÉCNICA E EXTENSÃO RURAL DO ESTADO DE MINAS GERAIS (EMATERMG). ICMS Solidário (2013). Disponível em: <http:// www.emater.mg.gov.br/portal.cgi?flagweb = site_ tpl_paginas_internas2\&id=7050\#.V1O01HarTnA $>$. Acesso em: 23 set. 2015.

FUNDAÇÃO JOÃO PINHEIRO (FJP). DataGerais (1999-2012). Disponível em: <http://datagerais.fjp. mg.gov.br/>. Acesso em: 1 jul. 2015.

Produto Interno Bruto de Minas Gerais (2012). Disponível em: <http://www.fjp.mg.gov.br/index.php/ produtos-e-servicos1/2745-produto-interno-bruto-deminas-gerais-pib-2>. Acesso em: 1 jul. 2015.

GRIFFITHS, W.; HILL, C.; JUDGE, G. G. Learning and practicing econometrics. New York: John Wiley \& Sons Inc., $1993.866 \mathrm{p}$.

GRISA, C.; SCHNEIDER, S. Três gerações de políticas públicas para a agricultura familiar e formas de interação entre sociedade e Estado no Brasil. In: GRISA, C.; SCHNEIDER, S. (Orgs.). Politicas públicas de desenvolvimento rural no Brasil. Porto Alegre: UFRGS, 2015.

GUJARATI, D. Basic econometrics. 2. ed. New York: McGraw Hill Company, 1998.

HSIAO, C. Analysis of Panel Data. 2. ed. Cambridge: Cambridge University Press, 2003.

INSTITUTO BRASILEIRO DE GEOGRAFIA E ESTATÍSTICA (IBGE). Censo Agropecuário (2006). Disponível em: <http://www.ibge.gov.br/home/ estatistica/economia/agropecuaria/censoagro/>. Acesso em: 4 ago. 2015.

. Sinopse do Censo Demográfico (2010). Minas Gerais. Disponível em: < http://www.censo2010.ibge. gov.br/sinopse/index.php?uf $=31 \&$ dados $=21>$. Acesso em 15 de outubro de 2016.

Pesquisa Nacional por Amostra de Domicílios

(2011). Disponível em: <http://www.ibge.gov.br/ 
home/estatistica/populacao/trabalhoerendimento/ pnad2011/>. Acesso em: 10 jul. 2015.

JUDGE, G. et al. Introduction to the Theory and Practice of Econometrics. New York: John Wiley \& Sons Inc., 1982.

KAGEYAMA, Ângela. Produtividade e renda na agricultura familiar: efeitos do Pronaf-Crédito. In: Revista Agricultura em São Paulo, São Paulo: IEA, vol. 50, n. 2, jul./dez. 2003.

KEYNES, J. M. The general theory of employment, interest and money. UK, Palgrave Macmillan, 1936.

MATTEI, L. Pronaf 10 anos: mapa da produção acadêmica. Brasilia: MDA, 2006.

Políticas de apoio ao desenvolvimento da agricultura familiar no Brasil: o caso recente do Pronaf. Revista Econômica do Nordeste, Fortaleza, v. 38, n. 1, p. 143-158, jan./mar. 2007.

PEREIRA, E, L.; NASCIMENTO, J. S. Efeitos do Pronaf sobre a produção agrícola familiar dos municípios tocantinenses. Revista de Economia e Sociologia Rural, Piracicaba/SP, v. 52, n. 1, p. 139-156, jan./mar. 2014.

RICETO, Á.; JUNIOR, J. C.; DE CARVALHO, E. R. Balanço de investimentos do Pronaf em Minas Gerais: uma tentativa de inserção da agricultura familiar no mercado. In: Encontro de Grupos de Pesquisa, 2, Uberlândia, 2006. p 1-11.

RUA, M. G. Análise de políticas públicas: conceitos básicos. In: RUA, Maria das Graças; VALADÃO, Maria Izabel. O Estudo da Política: Temas Selecionados. Brasília: Paralelo 15, 1998.
. Avaliação de políticas, programas e projetos: notas introdutórias. Brasília: ENAP, 2000.

. Políticas públicas. Florianópolis: Departamento de Ciências da Administração/UFSC, 2009.

SCHUMPETER, J. A. The Theory of Economic Development: An Inqury into Profits, Capital, Credit, Interest, and Business Cycle (1911/1934). Translated from the German by Redvers Opie, New Brunswick (USA) and London (U.K): Trasaction Publishers, 1934.

SILVA, S. P. Políticas Públicas e agricultura familiar: uma abordagem territorial do PRONAF no Médio Jequitinhonha. 2008. 158f. Dissertação (Mestrado em Economia) - Universidade Federal de Viçosa, Viçosa, MG.

STIGLITZ, J. Globalization and its discontents. New York, USA: W.W Norton Company, 2002.

UNIVERSIDADE FEDERAL DE JUIZ DE FORA (UFJF). Agenda de Desenvolvimento da Zona da Mata (2011). Disponível em: <http://www.ufjf.br/secom/ files/2011/09/Agenda-documento-Final-I-10-06-2011. pdf > . Acesso em: 11 ago. 2015.

VEIGA, J. E. Agricultura familiar e sustentabilidade. Cadernos de Ciência \& Tecnologia, Brasília, v. 13, n. 3, p. 383-404, set./dez. 1996.

WANDERLEY, M. N. B. Raízes históricas do campesinato brasileiro. Agricultura familiar: realidade $e$ perspectivas, Passo Fundo, v. 3, p. 21-55, 1999.

YOUNG, C. E. F. Aspectos sociais e econômicos do desmatamento em áreas de mata atlântica. Universidade Federal do Rio de Janeiro, 1999.

Todo o conteúdo deste periódico, exceto onde estiver identificado, está licenciado sob uma Licença Creative Commons (cc by 4.0). 
